\title{
Software Patents and Open Source Models in Europe: Does the FOSS community need to worry about current attitudes at the EPO?
}

\author{
Noam Shemtov ${ }^{l}$
}

DOI: $\underline{10.5033 / \text { ifosslr.v2i2.43 }}$

\begin{abstract}
The growing popularity of free and open source software (hereinafter 'FOSS') and the equally significant growth in the number of software patents give rise to the question of whether both models can live in peace, side by side, or does the latter pose a threat to the former. The focal point of this paper is the scope of patent protection to software products in EPC countries, particularly in the light of of the FOSS development environment.. Software patents are of great interest to the FOSS community. Modern computer programs are complex. They are developed incrementally where each software generation builds upon the previous one. Avoiding an inefficient re-invention of the wheel, programmers are typically combining thousands of different programs and algorithms in an innovative manner in order to produce the requisite final product. Here is where software patents become relevant. If a large number of those fundamental building blocks are unusable due to patent protection, a type of a 'tragedy of the anticommons' emerges. Hence, developers that may reasonably rely on FOSS licenses to incorporate the licensed software into their programs may later on realize that their actions amount to patent infringement. Obviously, this might have a chilling effect on the development and adoption of FOSS products.
\end{abstract}

\section{Keywords}

Patents; European Patent Convention; Free and Open Source Software; Software Patents;

\section{Info}

This item is part of the Articles section of IFOSS L. Rev. For more information, please consult the relevant section policies statement. This article has been independently peer-reviewed.

1 Noam Shemtov is a lecturer in IP and Computer \& Communication Law in the Centre for Commercial Law Studies, Queen Mary, University of London. 


\section{Introduction}

The growing popularity of free and open source software (hereinafter 'FOSS') and the equally significant growth in the number of software patents give rise to the question of whether both models can live in peace, side by side, or does the latter pose a threat to the former. The focal point of this paper is the scope of patent protection to software products ${ }^{2}$ in EPC countries ${ }^{3}$. But before one ventures into the realms of patent law, it may be useful to recall why is it that software patents are of significant interest to the FOSS community. Modern computer programs are complex. They are developed incrementally where each software generation builds upon the previous one. Avoiding an inefficient re-invention of the wheel, programmers are typically combining thousands of different programs and algorithms in an innovative manner in order to produce the requisite final product. Here is where software patents become relevant. If a large number of those fundamental building blocks are unusable due to patent protection, a type of a 'tragedy of the anticommons' emerges. In other words, integrating all those programs and algorithms may involve the use of patented products or processes. Hence, developers that may reasonably rely on FOSS licenses to incorporate the licensed software into their programs may later on realize that their actions amount to patent infringement. It is not surprising, therefore, that FOSS proponents are concerned that the possibility of these looming patents may have a chilling effect on the development and adoption of FOSS products. ${ }^{4}$ The question is therefore whether some of the aforementioned building blocks could be locked away under proprietary patent locks and keys.

\section{How it all started: A snapshot of the U.S. position}

As far as sheer numbers are concerned, the answer appears to be positive. By 2007, the United States Patent and Trademark Office had already granted 200,000 patents that may be termed as software patents ${ }^{5}$, and it continues to issue such patents at a rate of 20,000 per year. ${ }^{6}$ In the FOSS context, one study found that Linux operating system potentially infringes 283 software patents. Thus, the software-related legal landscape is already peppered with various patents and appears to get more congested by the day. In order to assess whether software patents pose a threat to the FOSS model it is necessary to examine the nature of such patents and the circumstances under which they may be granted. The answer, of course, is jurisdiction-dependent. It is the latter issue

2 As discussed below, a more appropriate terminology in the European context is 'computer implemented' inventions.

3 Patent law is not harmonised across the European Union. Thus, mentions in this paper to patentability in Europe refer to European Patent Organisation (EPO), which is an intergovernmental organisation that was set up on 7 October 1977 on the basis of the European Patent Convention (EPC) signed in Munich in 1973.

4 Greg DeKoenigsberg, The Red Hat Patent Promise: Encouraging Innovation, RED HAT MAG., Nov. 2004, http://www.redhat.com/magazine/001novo4/features/patents/.

5 i.e. patents granted over software programs designated as 'products' or 'processes' implemented via software programs, including, for example, the automation of business methods.

6 James Bessen \& Robert M. Hunt, An Empirical Look at Software Patents, 16 J. ECON. \& MGMT. STRATEGY 157, 158 (2007). DOI: $10.1111 / \mathrm{j} .1530-9134.2007 .00136 . \mathrm{x}$

7 Press Release: Open Source Risk Management, Results of First-Ever Linux Patent Review Announced, Patent Insurance Offered by Open Source Risk Management, http://www.osriskmanagement.com/press-releases/pressrelease-080204.pdf 
that stands at the centre of this paper and in particular software patentability in Europe.

Software patents have proliferated in the last twenty years. The trend started in the United States. It was the Supreme Court of the United States that first grappled with the issue of patentability of software related inventions in a series of three landmark cases. ${ }^{8}$ While it is a long established principle that a pure mathematical algorithm cannot be patented, ${ }^{9}$ it is less clear how far one needs to move away from the realms of the mere abstract in order to render the subject matter of a patent application patentable. Recently, and after much anticipation, the Supreme Court of the United States has struck down the 'machine-or-transformation' test, established by the majority of the Court of Appeal of the Federal Circuit in re Bilski, as the sole test of software patentability. ${ }^{10}$ The Supreme Court returned the 'machine-or-transformation' test to its original status as a 'useful and important clue, an investigative tool' for establishing eligibility. Hence, it is now clear that software methods as well as business methods are eligible for patent protection in the U.S., as long as the claims are drafted so that the claimed subject matter cannot be said to be purely abstract. Of course, an applicant still has to satisfy the requirements for novelty and non-obviousness.

Thus, at least as far as the U.S. is concerned, software patents are a fact of life that the industry, including the FOSS community, must learn to live with. But how did we get to this stage? Why does the industry wilfully shackle itself in this manner? After all it is not only FOSS friendly entities that bear the consequences. ${ }^{11}$ In fact, during the Nineties some of the companies that have recently attempted to enforce their software patents against various parties expressed somewhat different views in this context. For example, in 1991 Bill Gates, the founder of Microsoft Corporation, referring to software patents, stated:

\section{"If people had understood how patents would be granted when most of today's ideas were invented and had taken out patents, the industry would be at a complete standstill today. ${ }^{\prime \prime 2}$}

Oracle's statement, submitted to the hearings on software patentability at the US Patent Office in 1994, reads:

\footnotetext{
"Oracle Corporation opposes the patentability of software. The Company believes that existing copyright law and available trade secret protections, as opposed to patent law, are better suited to protecting computer software developments. Patent law provides to inventors an exclusive right to new technology in return for publication of the technology. This is not appropriate for industries such as software development in which innovations occur rapidly, can be made without a substantial capital investment, and tend to be creative combinations of previously-known techniques."
}

8 Gottschalk v. Benson, 409 U.S. 63, 73 (1972); Parker v. Flook, 437 U.S. 584, 596 (1978); Diamond v. Diehr, 450 U.S. 175, 193 (1981).

9 For the US, see, for ex', Le Roy v. Tatham, 55 U.S. 156, 175 (1852); for the EPC, see Art. 52(2)(a).

10 Bilski v. Kappos, No. 08-964 (US June 28, 2010)

11 See, e.g. NTP action against Research in Motion for infringement of its software patents. The case was settled in March 2006, with RIM paying NTP \$612.5 million to make NTP go away, NTP, Inc v. Research in Motion, Ltd 418 F.3d 1282 (2005). In 8 July, 2010 NTP filed a lawsuit Apple, Inc., Google Inc., HTC Corp., LG Electronics Inc., Microsoft Corporation, and Motorola, Inc. in the United States District Court for the Eastern District of Virginia for infringing NTP's eight patents related to the delivery of electronic mail over wireless communications systems.

12 L. Lessig 2002-07-24: Keynote to OSCON 
Viewed today, these statements are difficult to reconcile with the above companies' patent enforcement policy.

The reasons for this sudden change of heart are multiple. Initially, the great run to patent law started after U.S. courts begun to erode the scope of protection available to computer programs under copyright law in the early nineties. Thus, for example, in Computer Associates v. Altai the court restricted the scope of protection available to computer programs under the AbstractionFiltration-Comparison test. ${ }^{13}$ A couple of years later, the court in Lotus v. Borland suggested that the available scope of protection should be trimmed even further as the initial inquiry of a court in cases involving copyright infringement of computer programs must be whether the subject matter taken amounts to idea, procedure, process, system or method of operation. ${ }^{14}$ As various software companies flocked to the USPTO, other software companies found it more and more difficult to remain passive. Thus, it can be said that many of the parties seeking patent protection nowadays are doing so for reasons that have little in common with the objectives and public policy considerations underlying patent law. ${ }^{15}$ To name but a few, nowadays patent protection is often sought for reasons such as attracting investors - by indicating that the company is a significant technological player, ${ }^{16}$ as a defense strategy - being able to cross license patents with other market player ${ }^{17}$ and participation in a patent pooling model. ${ }^{18}$

Whatever the reasons for obtaining such patents might be, as HP's Vice President of Linux, Martin Fink, has said: ""[a]t the end of the day, software patents are a way of life. To ignore them is a little bit naive. ${ }^{19}$ Whether we like it or not, the software community must learn to deal with the availability software patents in the U.S.

But are software patents 'a way of life' in Europe too? Can one obtain a 'software patent' in Europe in a manner similar to that available in the U.S.? It is a common wisdom that the situation in Europe is not similar to that in the U.S., in that it is more difficult to obtain patent protection over software products in Europe. But what exactly does that mean? Is it possible for one to obtain a patent for a software product in Europe and if so, under which circumstances?

\section{EPC: Legislative Framework}

Prior to my examination of European jurisprudence regarding patent protection for software products, it should be noted that patent law is not harmonized at European Union level. ${ }^{20}$ Thus,

13 Computer Assocs. Int'l v. Altai, 982 F.2d 693, 705 (2d Cir. 1992). The court found that the part taken by the defendant did not amount to the plaintiff's program's core protectable expression.

14 Lotus Dev. Corp. v. Borland Int'1, 49 F.3d 807, 819 (1st Cir. 1995). Here the court refused to hold that a program's menu command hierarchy was a protectable subject matter under copyright law.

15 Large software companies are not likely to gain meaningful financial rewards from enforcing their patents; see, e.g., Ronald J. Mann, Do Patents Facilitate Financing in the Software Industry 83 TEX. L. REV. 961, (2005), at 996.

16 Ibid, 993-995.

17 Ibid, 990

18 Patent pooling is a derivative of the cross licensing concept. See, e.g., Open Invention Network, http://www.openinventionnetwork.com/about.php

19 Stephen Shankland, HP: Don't Like Software Patents? Learn to Deal, ZDNET NEWS, Feb. 15, 2005, http://news.zdnet.com/2100-3513-22-141325.html.

20 There are a few exceptions in specific areas where harmonising measures were taken on an EU level; see, e.g., The Biotechnology Directive (98/44/EC). 
references in this paper to European patent law or European jurisprudence are not made in a European Union context. Although the European Commission sought in the past to harmonized patent law within European Union with respect to software patents, this attempt was overwhelmingly rejected by the European Parliament in $6^{\text {th }} \mathrm{July,} 2005 .^{21}$ Although EU harmonization in this context may return in the future to the public agenda under initiatives such as Community Patent or the European Patent Litigation Agreement (EPLA), this paper addresses the question of patentability of software products under the present legislative framework; i.e. the European Patent Convention (EPC). The EPC is an intergovernmental treaty that is independent of the European Union; its members extend beyond membership of the EU. ${ }^{22}$ The EPC is mainly concerned with granting European Patents. ${ }^{23}$ This was facilitated by the establishment of the European Patent Office (EPO). When the EPC was formulated it was decided that in order to have an effective granting process it was also necessary to harmonise the basic national rules of patent law; i.e. rules regarding patentability and validity. Thus, rules concerning patentablity and validity are harmonised both at EPO and national law levels. On the other hand, rules concerning issues such as infringement, enforcement, renewal, revocation and litigation are governed by national law. It is noteworthy that the EPC being independent of the EU also means that decisions of EPO Boards of Appeal are not, strictly speaking, binding on national courts but could be described as being of highly persuasive authority. ${ }^{24}$

\section{Software patents and computer programs 'as such'}

'Software patents' is a term best avoided in the context of patentability of computer programs in Europe. For reasons discussed below it is suggested that 'computer implemented inventions' is a more appropriate term. In order to obtain a patent, an applicant is required to establish that: (a) the claimed subject matter relates to an invention, ${ }^{25}$ (b) the said invention is novel, ${ }^{26}$ (c) it involves an inventive step $^{27}$ and, (d) has an industrial application. ${ }^{28}$ Article 52 deals with patentable inventions. Inter alia, it provides a list of 'non-inventions', i.e. a list of subject matter that are to be considered as falling outside its definition of 'invention' and hence non-patentable. Thus, an application claiming a subject matter that falls under the scope of the non-invention list is not patentable and no enquiry as to its novelty, inventive step or industrial application needs to be carried out. Article 52(2) states, inter alia, ${ }^{29}$ that "mathematical methods ..., schemes, rules and methods for performing mental acts, playing games or doing business, programs for computers and the presentation of information" are not to be considered as inventions. However, Article 52(3)

21 On $6^{\text {th }}$ June 2005 the European Parliament rejected Commission proposal COM(2000)0199 (a proposal for a European Union directive aimed to harmonise national patent laws and practices concerning the granting of patents for computerimplemented inventions) by 648 votes to 14 with 18 abstentions.

22 As of 1 May, 2010 the EPC consisted of the following 37 member states: Albania, Austria, Belgium, Bulgaria, Switzerland, Cyprus, Check Republic, Germany, Denmark, Estonia, Spain, Finland, France, United Kingdom, Greece, Croatia, Hungary, Ireland, Iceland, Italy, Liechtenstein, Lithuania, Luxemburg, Latvia, Monaco, FYROM, Malta, Netherland, Norway, Poland, Portugal, Romania, Sweden, Slovenia, Slovakia, San Marino, Turkey.

23 Giving rise to a portfolio of national patents that are in force in EPC member states designated by the applicant.

24 Thus, a national court deciding on a domestic patent application is not bound by the approach taken at the EPO, although it is nevertheless more likely to follow it than not.

25 EPC, Art. 52.

26 EPC, Art. 54.

27 EPC, Art. 56.

28 EPC, Art. 57.

29 The 'non inventions' list under Art. 52 also covers scientific theories, discoveries and aesthetic creations. 
provided that the list of excluded subject matter provided for in Article 52(2) is so excluded only to the extent the excluded thing is claimed 'as such'.

It is suggested that it is the aforementioned text of the EPC that gives rise to the ongoing uncertainty of the scope of the exclusion from patentability of computer programs. The meaning of 'as such' in the context of computer programs has been anyone's guess during the past two decades. The ensuing uncertainty has been illustrated by a series of decisions of different EPO Boards of Appeal, a referral to the Enlarged Board of Appeal by the President of the EPO, as well as by a number UK court decisions seeking to apply the UK equivalent of Article 52. Not only were those English decisions irreconcilable with those of the EPO, but to a certain extent the said EPO decisions appeared to be irreconcilable with one another.

\section{Computer-implemented inventions}

It is clear from the text of Article 52 that computer programs 'as such' cannot be claimed in a patent application. Thus, a claim to a computer program in the narrow sense of the word, e.g. which literally claims computer executable instructions or an executable software module clearly falls under the exception of Article 52(3). However, things become less clear where claims are not literally formulated as aforementioned, but are rather directed to computer systems, computerimplemented methods, computer program products and the storing of computer programs. It should be noted that the underlying method of performing the latter type of claims is often identical to that of performing the former one. Rather than using 'computer programs' or 'software', for the purpose of clarity 'computer-implemented' inventions is used as a term to encompass inventions the implementation of which involves the use of a computer, computer network, or other programmable apparatus, with features realized wholly or partially by means of a computer program. Thus, the main question is when does an application for a computerimplemented invention relate to a computer program "as such", thus becoming a 'non-invention' under Article $52^{30}$ ?

The starting point of the present discussion is the Technical Board of Appeal landmark decision in Vicom. ${ }^{31}$ The case concerned claims to a method of digitally processing images and to an apparatus, which may be a general-purpose computer, for carrying out that method. The Technical Board of Appeal stipulated that an invention is patentable if it satisfies the normal requirements for patentability under the EPC and should not be prejudiced against simply because its implementation required modern technical means in the form of a computer program. The Board then stated: "decisive is what technical contribution (emphasis added) the invention as defined in the claim when considered as a whole makes to the known art." This later became known as the 'technical contribution approach'. According to this approach, when examining a patent application in this context, one should disregard the form or kind of claim and concentrate on its content in order to identify the real contribution which the subject-matter claimed, considered as a whole, adds to the known art. If this contribution is not of a technical character (i.e. if it falls

30 However, this is not the only relevant question; the claimed invention's 'technical character' is of significant importance as well.

31 Vicom (1986) T208/84, [1987] OJ14. 
exclusively within one of the excluded $\operatorname{areas}^{32}$ ), there is no invention within the meaning of Article $52(1)$.

The first step of departure from the so-called technical contribution approach was in T1173/97. In this case the examining division found that there was an 'invention' and was prepared to grant a patent in respect of claims that were accepted under Vicom's technical contribution approach, since the application manifested technical contribution. However, the application at stake also included claims directed not to the system as a whole or a method of operating the system as a whole, but to a program, in two forms, as follows:

\begin{abstract}
"A computer program product directly loadable into the internal memory of a digital computer, comprising software code portions for performing the steps of [independent method] claim 1 when said product is run on a computer," and "A computer program product stored on a computer usable medium, comprising: computer readable program means for causing a computer to [carry out the various steps of method claim 1]." The technical board of appeal held that a computer program, claimed on its own, is not excluded from patentability if the program, when running on a computer or when loaded into a computer, brings about a technical effect which goes beyond usual physical interaction between the program and the computer."
\end{abstract}

Rather than looking for a technical contribution to the state of the art as in Vicom, the board stated that computer programs must be considered as patentable inventions where they have a technical character. This 'technical character' or 'technical effect' should be understood as a further technical effect in that it goes beyond the normal technical effect that is inherent to a software-hardware environment. The board emphasized that in this context it made no difference whether or not the program was claimed by itself or as part of a system. Thus, it was not the wording of the claims that matter but rather their content. According to the board, when examining the content of an application for a 'technical effect', the inquiry should be conducted independently of the prior art. Thus, the so called further technical effect does not have to be novel.

The abandonment of the 'contribution approach' was further elucidated in the subsequent Pension Benefit Systems decision. ${ }^{33}$ In that case, the objection raised by the European Patent Office was that the claims in the application related to a computerized method of doing business, a category excluded from patentability under Article 52 of the EPC. The examination division maintained that, since the contribution that the claimed subject-matter made to the known art was solely within the 'business' field, the contribution is to be regarded as non-technical and the application should be refused on the basis that the claimed subject matter did not constitute an invention. In the Technical Board of Appeal's view, the 'contributions approach' confused the requirement of 'invention' with the requirements of 'novelty' and 'inventive step', since it looked at the contribution made by the invention to the prior art. According to the board, an inquiry in relation to the state of the art has no place in an examination under Article 52 and should be conducted only with relation to an examination for novelty and inventive step. Thus, the board held that an apparatus (i.e. a computer loaded with the program) for carrying out an activity excluded as such from patentability by Articles 52(2) and (3) EPC was not, in itself, excluded from patentability

32 An excluded subject matter is regarded, by definition, as non-technical.

33 T931/95 (OJ EPO 2001, 441) 
under Article $52 .{ }^{34}$

However, that decision did not extend the same logic to methods employing technical means. While the apparatus claims were held to comply with the requirements of Article 52, the corresponding method claims were held not to employ technical means and thus fall foul of Article 52. It should be noted that the apparatus claims in Pension Benefits did not get far. The board in Pension Benefits held that ultimately the application was bound to fail under Article 56 for lacking inventive step since the contribution it made to the known art (i.e. to the field of 'doing business') lay solely within an excluded field. Thus, the board held that where the contribution is made exclusively within an excluded field, then by definition it does not possess a technical character. Where a feature of a claim does not have a technical character or a technical effect, it is deemed to be within the knowledge of the skilled person for the purpose of assessment under Articles 54 and 56.

The decision of the board in Pension Benefits on the non-compliance of the methods claims with the requirements of Article 52 was explicitly rejected by the decision of the board in Hitachi ${ }^{35}$. Thus, in Hitachi the technical board of appeal followed the board's decision in Pension Benefits on the apparatus claims but rejected it on the method claims. The board held that claims involving technical means were not excluded from patentability under Article 52. It followed that claims directed to a method of operating a computer involved a computer, which is a physical object of technical nature, and thus could not be excluded from patentability as non-inventions.

The decision in Microsoft ${ }^{36}$ extended this logic even further. In this case the board held that claims to a program ('computer executable instructions') on a computer readable medium also avoided Article 52 exclusion. The board reasoned that the subject matter of the contested claim had a technical character since it related to a computer readable medium, which is a technical product involving a carrier. Thus, while T1173/97 suggested that it was not the wording of the claims that matter but rather their content, Microsoft clearly stands for the proposition that in order to avoid Article 52 exclusion, an applicant merely needs to make sure that claims to computer programs ${ }^{37}$ should be drafted so as to explicitly mention the use of computer or computer readable storage medium. Since a computer or a carrier is a 'technical product', the application would manifest the requisite technical effect in order to avoid Article 52 exclusion. Similarly to the approach taken in Pension Benefit and followed in Hitachi, the technical Board in Microsoft shifted the focus of it examination to the assessment for inventive step. Thus, while any technical means was sufficient to overcome the exclusion of Article 52, a 'further' technical means was still required for the assessment for inventive step. It is features of the claims that contribute to the 'further' technical character of the claimed subject matter that are taken into account for the assessment of inventive step. Since on the fact of the case the Technical board found that such further technical effect was present and non-obvious, the appeal was allowed.

The approach taken by the technical board in Microsoft has not been challenged by any

34 Since the board held that the apparatus in question was not a computer program nor a method of doing business 'as such', it was an 'invention' within the meaning of Article 52(1).

$35 \mathrm{~T} 258 / 03$.

$36 \mathrm{~T} 424 / 03$.

37 As mentioned, claims to computer programs in the narrow sense of the word are excluded from patentability under Article 52. 
subsequent decision and may be considered as representing the present legal position in the EPO. ${ }^{38}$ Subsequent decisions further elucidated and developed this approach. In Duns ${ }^{39}$ the technical board of appeal concluded that some features of a claim which, when considered alone, might fall under the exclusion of Article 52, could nevertheless be taken into account for the assessment of inventive step.

\section{A shift in focus of assessment of patentability of 'computer implemented inventions': Art. 56}

As we have seen, computer implemented inventions find it relatively straightforward to pass the patentability hurdle of Article 52 under the currently prevalent approach of the EPO boards of appeal. Indeed, according to this approach any technical means will do in order to render a claimed subject matter 'an invention' and thus comply with the requirements of Article $52 ;{ }^{40}$ it is not surprising therefore that many refer to the said approach as the "any hardware" or "any technical means" approach. ${ }^{41}$

This, however, does not mean that such inventions are easily patentable and that the area in which the contribution made to the state of the art is of no relevance. This factor is still of crucial importance to the invention's patentability. But under the 'any hardware' approach, the said factor is now evaluated under the assessment for inventive step. As mentioned, features that lay exclusively in an excluded field are not considered as having a technical effect, while features that are held to be not within an excluded field may have a technical effect and could therefore be taken into consideration when assessing inventive step. However, it should be noted that the former type of features may still have a role to play under an inventive step assessment.

This was made clear in Duns, ${ }^{42}$ where the technical board of appeal was required to assess the patentability of an application, the main request of which concerned a method for estimating sales activity of a product at sales outlets. The board explained that when examining patentability of an invention in respect of a claim, the claim must be construed to determine the technical features of the invention, i.e. the features which contribute to the technical character of the invention. Although it is legitimate to have a mix of technical and non-technical features appearing in a claim, the board noted that novelty and inventive step can be based only on technical features, which thus have to be clearly defined in the claim. The board stated that non-technical features, to the extent that they do not interact with the technical subject matter of the claim for solving a technical problem, ${ }^{43}$ i.e. non-technical features "as such", do not provide a technical contribution to the prior art and are thus to be ignored in assessing novelty and inventive step. However, according to the board, such non-technical features may nevertheless be used for the purpose of the problem-and-solution approach that was developed as a test for whether an invention meets the

\footnotetext{
38 See G3/08, 10.8 .2

39 T154/04 (OJ EPO 2008, 46)

40 This is so since Article 52(2) EPC does not exclude from patentability any subject matter or activity having technical character, even if it is related to the items listed in this provision since these items are only excluded "as such".

41 See, G3/08, 10.6

42 Supra, 39.

43 The general approach in the EPO for assessing inventive step being the 'problem and solution' approach.
} 
requirement of inventive step, where the problem must be a technical problem.

Defining the technical problem without referring to non-technical features, however, may be difficult where the actual novel and inventive concept making up the core of the claimed invention resides outside any technological field, as it is frequently the case with computer-implemented inventions. Thus, defining the problem without referring to this non-technical part of the invention, if at all possible, will generally result either in an unintelligible vestigial definition, or in an contrived statement that does not adequately reflect the real technical contribution provided to the prior art. ${ }^{44}$ The Board therefore allowed the "aim to be achieved in a non-technical field to appear in the formulation of the problem as part of the framework of the technical problem that is to be solved." ${ }^{" 5}$ Nevertheless, it is clear that without an inventive technical contribution to the state of the art, technical being in the realms outside the excluded fields as defined under Article 52, an invention may not be patentable. Thus, the crux of the matter in such applications is whether the invention in question manifests a non-obvious technical contribution to the state of the art. A contribution that falls squarely within an excluded field is not 'technical' and its obviousness is therefore of no relevance. This is clearly different from the position under U.S. law, where the 'non-obviousness' of an invention may reside in what may be termed as non-technical under EPO jurisprudence but may nevertheless render the invention in question patentable under U.S. law.

It follows that in the heart of the question of patentability of computer implemented invention in the EPO lies the concept of technicality, whether referred to as 'technical effect' or 'technical character'. But what does one mean when referring to 'technical' in this context? It is clear that the usual interaction between software and hardware is of technical nature. This, indeed, is taken into account when rendering the claimed subject matter 'an invention' under Article 52. It will also be taken into account when carrying out an assessment under Article 56. However, if no further technical feature could be identified, such technical features would quite clearly be obvious to the skilled person as they form part of the common general knowledge in this field. ${ }^{46}$ Thus, a technical means that goes over and above the abovementioned usual interaction between hardware and software is needed in order to render an invention patentable. This raises the question of which types of claim features may possess such technical nature. Unfortunately, to date the EPO boards of appeal always refrained from providing a definition to the term technical, even in the form of general guidelines. The same position appears to apply to the assessment of the activity of programming. While it is clear that every instance of programming involves technical considerations since it is concerned with defining a method that could be carried out by a machine, this in itself is not enough to establish that the program that results from the said programming has a technical character. Again, something additional is needed; it should be demonstrated that the programmer had technical considerations beyond merely finding a programming algorithm to carry out the requisite procedure.

44 Supra 39, para 16.

45 Ibid.

46 The skilled person is skilled in the field of information technology, aware of common general knowledge in information technology and having no knowledge of non-technical fields. 


\section{In the meantime in England...}

English Courts have been grappling with early inconsistent EPO case law for most of the past decade. In this context one must bear in mind that decisions of the EPO boards of appeal are not binding on national courts of EPC countries but are merely persuasive. The first English case that reviewed the EPO trilogy of decisions discussed above, highlighting the difficulties in reconciling them with each other as well as with Vicom, was Aerotel. ${ }^{47}$ In this case, the Court of Appeal examined the said EPO decisions, identifying a clear inconsistency between their different approaches. Describing the Pension Benefit and Hitachi approaches as 'The Lord Giveth, the Lord Taketh away', the Court of Appeal explained: 'the giving is the passing of Art. 52(2), the taking away being the device of treating the excluded matter as known' ${ }^{48}$ In contrast, the Microsoft/Data Transfer approach was described as 'the Lord Giveth but the Lord Doth not Always Taketh away'. ${ }^{49}$ The Court also emphasized that none of the trilogy decisons was reconcilable with Vicom and its technical contribution approach. The Court acknowledged the need to maintain a harmonized position within the EPC countries and vis - a`- vis the EPO Boards of Appeal. However, it felt that that as there was uncertainty as to which approach prevailed within the EPO itself, it should follow the long standing approach of the English courts-the technical contribution approach, as established in Vicom and endorsed by the Court of Appeal in Merrill Lynch ${ }^{50}$ and Re Gale. ${ }^{51}$ The court emphasized its willingness to reconsider its position only in the event of the Enlarged Board of Appeal ruling on the issue and laying the uncertainty within the EPO to rest. It is yet to be seen whether the recent refusal of the Enlarged Board of Appeal to consider the questions referred to it by the then President of the EPO due to lack of inconsistency in the caselaw of the boards of appeal would satisfy the English Court of Appeal that the EPO boards of appeal now speak with one voice on the matter. ${ }^{52}$

Unsurprisingly, subsequent English High Court decisions appeared to follow the same footpath. ${ }^{53}$ The technical contribution approach got further support when the Court of Appeal revisited the aforementioned issues in Symbian. ${ }^{54}$ Similarly to its decision in Aerotel, the court reviewed previous English authorities as well as decisions of the EPO boards of appeal and unsurprisingly concluded that English courts are still bound to adhere to the technical contribution approach for assessment under Article 52, while it appeared that the EPO had abandon that approach and now allows virtually any application involving a computer program to pass the test of Article 52, simply due to the technicality inherent in the interaction between a program and a computer onto which it is loaded. However, using a more conciliatory tone than in Aerotel, the court opined that the important thing was that both approaches sought to identify a technical contribution. ${ }^{55}$ Whether

47 Aerotel Ltd (a company incorporated under the laws of Israel) v Telco Holdings Ltd, Telco Global Distribution Ltd, Telco Global Ltd [2006]

EWCA Civ 1371

48 Ibid, para 28.

49 Ibid.

50 Merrill Lynch's application [1989] RPC 561.

51 Gale's application [1991] RPC 191.

52 G 3/08.

53 E.g., see Halliburton v Smith [2005] EWHC 1623 (Pat); Shoppalotto.com's application [2005] EWHC 2416 (Pat); Cappellini's Application [2007] FSR 26; Raytheon's Application [2008] RPC 3; Autonomy Corporation Ltd [2008] EWHC 146 (pat)

54 [2008] EWCA Civ 1066

55 Whatever the actual terminology used may be. 
one seeks to identify such technical features while making an assessment under Article 52 or one under Article 56 would matter little in most cases as far as the final outcome of the case is concerned.

It is true that whether one examines an application for technical contribution under Article 52 or Article 56 may lead to the same outcome as an application that may be refused by an English court for being a non-invention due to lack of technical features that go beyond these which are inherent in a computer-software environment should, in principle, be refused by an EPO board of appeal for lack of inventive step under Article 56. This conclusion, however, may be valid if one assumes that what may constitute a technical feature before an EPO board of appeal for the purpose of Article 56 is also likely to amount to technical contribution before an English court when examining a case under Article 52. It is arguable whether that is indeed the case.

\section{The amorphous nature of 'technical character'}

The elusive 'further' or 'additional' requisite technical effect appears to be assessed on a case by case basis rather than by reference to an established set of principles and guidelines. We know that there is no general definition to what constitutes 'technical' and we also know that there are clearly grey areas where it would be difficult to anticipate whether such technical effect is present. Can any lessons nevertheless be learned from the case law of the EPO boards of appeal regarding 'technical character'?

A review of the many instances in which the boards of appeal found computer implemented inventions to have or not to have a technical character and thus manifest an inventive step is beyond the scope of this paper and in any event would be a little benefit as such decisions are limited to their particular facts. However, a number of helpful observations can be made in the context of computer implemented inventions. It appears that the term 'technical' may include features such as the processing of physical data parameters or control values of an industrial process, physical features of an entity (e.g. memory ports) and perhaps most relevant for the FOSS community, processing which affects the way a computer operates (e.g. saving memory, increased speed, security of a process, the rate of data transfer etc'). There are, however, considerable grey areas and the outcome of many applications for computer implemented inventions is far from certain.

A favourite example of the author of this paper to the uncertainty concerning the outcome of applications for computer implemented inventions in this context is a fairly recent but scarcely cited decision of the technical board of appeal in Circuit simulation/Infineon Technologies. ${ }^{56}$ The application at stake concerned a computer implemented simulation or modelling method for testing the performance of an integrated circuit under the influence of a 1/f noise. It was based on a mathematical formula that generated random numbers that produced an exact $1 / \mathrm{f}$ noise into the simulation. The claimed method required shorter computing time and less storage space in designing integrated circuits. The claimed method accordingly made it possible to simulate noisy circuits on smaller computer systems, which were previously not powerful enough for that purpose, and to simulate large circuits, which previously could not have been simulated on any

$56 \mathrm{~T} 1227 / 05$. 
computer system whatsoever. In addition to claiming the method, the application contained claims for a computer program executing the method, a data medium holding the program, and a computer system on which the program was loaded. Unsurprisingly the board of appeal overturned the examining division decision to refuse the application on the ground that the simulation method claimed in it constituted a mental act or a mathematical method as such and was thus excluded from patentability under Article 52(2) as a non-invention. More interestingly though were the board's findings regarding the assessment for inventive step. It is noteworthy that the claimed method did not improve or affected the internal operation of a computer per se. As mentioned, at the heart of the application was an algorithm that made the simulation of an integrated circuit's design more effective. Thus, in essence, the claimed method consisted of a mathematical formula implemented in a computer program for simulating noise-affected circuits. The only thing that the claimed method produced was data, which was employed at a later stage, separately from the claimed method, in the physical activity of integrated circuit fabrication. Hence, the relevant industrial process, i.e. the fabrication of integrated circuits, was not part of the claimed method and was carried out at a different time and quite often at a different location from the simulation stage. Nevertheless, since according to the board of appeal the claimed method was a practical and practice-oriented part of the electrical engineer toolkit, rather than being a purely mathematical theory or a mental act, all steps relevant to the circuit simulation, including the mathematically expressed claim features, contributed to the technical character of the claimed subject matter. Thus, having the requisite technical effect, the said features were taken into consideration when assessing the invention for inventive step and resulted in the board's finding that the invention at stake manifested inventive step.

A careful examination of the board's decision reveals what might have been one of the main reasons for the board's finding: a public policy based analysis of the market for integrated circuits! Thus, analysing the present state of technology and needs of the twenty first century engineer, the board noted that an increasing number of fields in the engineering science use numerical simulation methods as a cost-effective alternative to expensive experimental investigations, which consume significant time and personal resources. In many industrial fields numerical simulation methods evolved to be a key technology and should, therefore, be eligible for protection. Accordingly, in the case before it, the Board held that the claimed simulation method must be regarded as a modern technical method, which forms an essential part of the fabrication process and precedes actual production as an intermediary step. In the light of the manner in which the industry is developing, the final implementation of the simulation outcome and the actual manufacturing process involves very little innovative effort if any at all. Furthermore, the Board pointed out that nowadays the development and production stages of integrated circuits are increasingly separated, materially and geographically, in a globally distributed industry. For these reasons, a simulation method should not be denied patent protection merely because it does not involve a physical stage.

It is suggested that this decision is a vivid example of the amorphous nature of the concept of technical character and the uncertainty which surrounds it. In this instance it enabled the board to engage in judicial activism where it explicitly identified what it deemed to be a need of the relevant industry and tailored its definition of what constitutes a technical character accordingly. 


\section{Summation}

While it is true that software patents are more prolific in the US, it is clearly wrong to assume that no such patents exist or could be granted in Europe due to the effect of Article 52(2) EPC. Although referred to as 'computer implemented' inventions rather than software patents, it has been demonstrated that in certain circumstances software features, which may cover aspects of FOSS development projects, are eligible for patent protection in Europe. The exact scope of such instances ultimately hinges on the specificities of the software in a given FOSS project and the meaning the court or board chooses to inject into the term 'technical' in each case. What is certain though is that it is not only the US patent regime that the FOSS community should be concerned with; when looking over one's shoulder, it may also prove wise to check what is brewing at the corridors of the EPO in Munich.

\section{Licence and Attribution}

This paper was published in the International Free and Open Source Software Law Review, Volume 2, Issue 2 (December 2010). It originally appeared online at http://www.ifosslr.org.

This article should be cited as follows:

Shemtov, Noam (2010) 'Software Patents and Open Source Models in Europe: Does the FOSS community need to worry about current attitudes at the EPO?', IFOSS L.

Rev., 2(2), pp $151-164$

DOI: $\underline{10.5033 / \text { ifosslr.v2i2.43 }}$

Copyright @ 2010 Noam Shemtov

This article is licensed under a Creative Commons UK (England and Wales) 2.0 licence, no derivative works, attribution, CC-BY-ND.

As a special exception, the author expressly permits faithful translations of the entire document into any language, provided that the resulting translation (which may include an attribution to the translator) is shared alike. This paragraph is part of the paper, and must be included when copying or translating the paper.

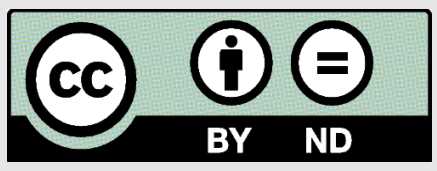

